\title{
The correlation between weakest configurations and yield strength of Zr- based metallic glasses
}

\author{
M.C. Li ${ }^{\mathrm{a}}$, M.Q. Jiang ${ }^{\mathrm{b}, \mathrm{c}}$, G. Ding ${ }^{\mathrm{a}, \mathrm{b}}$, Z.H. Peng ${ }^{\mathrm{a}}$, F. Jiang ${ }^{\mathrm{a}, *}$, L. He ${ }^{\mathrm{a}}$, J. Sun ${ }^{\mathrm{a}}$ \\ a State Key Laboratory for Mechanical Behavior of Materials, Xi'an Jiaotong University, Xi'an 710049, China \\ b State Key Laboratory of Nonlinear Mechanics, Institute of Mechanics, Chinese Academy of Sciences, Beijing 100190, China \\ c School of Engineering Science, University of Chinese Academy of Sciences, Beijing 100049, China
}

\section{A R T I C L E I N F O}

\section{Keywords:}

Metallic glasses

Yield strength

Solvent atoms

Free volume

\begin{abstract}
A B S T R A C T
A direct relationship between the yield strength and the atomic ratio of solvent ( $\mathrm{Zr}$ ) atoms in the $\mathrm{Zr}-\mathrm{Cu}-\mathrm{Al}-\mathrm{Ni}$ metallic glasses system is firstly uncovered. It is found that either shear modulus or yield strength decreases almost nearly with the increase in atomic ratio of $\mathrm{Zr}$. The origin of this relationship is ascribed to the preferential straining of the weakest configurations, which consist of the solvent-solvent bonds and the free volume concentrated in them. It is suggested that a higher atomic ratio of $\mathrm{Zr}$ corresponds to a larger amount of weakest configurations, which will facilitate the activation and the accumulation of the shear transformations and finally results in the lower yield strength. This finding may provide an effective strategy for designing high-strength metallic glasses by modifying the chemical composition.
\end{abstract}

\section{Introduction}

The structural picture of metallic glasses becomes clearer and clearer with durative efforts [1-5]. The solute-centered clusters and their efficient packing construct the short- and/or medium-range order. The long-range disorder can be achieved by linking these ordered clusters through excessive solvent atoms. Therefore, it is accepted that these structures on different length scales will determine the physical properties from relaxation (fast or slow) to deformation (elastic or plastic) [6-9]. For instance, Ma et al. [8] found that metallic glasses inherit shear/Young's modulus from their solvent atoms. This surprising finding substantiates the idea that the bonds of solvents could determine the shear modulus on the long-range scale $[7,8]$. Moreover, these loosely packed solvent-solvent junctions usually lead to additional scattering of transverse phonons in the $\mathrm{THz}$ region, which is quite common for various glasses $[10,11]$. Very recently, Ding et al. [12] introduced the concept of "flexibility volume", a volume-scaled vibrational mean square displacement of $\mathrm{THz}$ phonons, which can predict the shear modulus of metallic glasses quantitatively. This further confirms that solvent-solvent junctions can directly dominate the shear modulus of the metallic glasses. Meanwhile, it is well known that the shear modulus controls the energy barrier for relaxation and shear flow, as indicated in both the shoving model of Dyre [13] and the cooperative shear model of Johnson and Samwer [14]. Specifically, the yield strength in shear mode shows a linear relationship to the shear modulus with respect to the atomic ratio of solvent atoms for a variety of metallic glasses $[15,16]$. It is therefore expected that the solvent-solvent junctions will determine the plastic yielding of metallic glasses beyond the elastic range. However, this needs further experimental evidence.

In the present work, a series of metallic glasses with identical chemical constituents of $\mathrm{Zr}-\mathrm{Cu}-\mathrm{Al}-\mathrm{Ni}$ but different atomic ratio were selected as the model system. It is clearly demonstrated that the yield strength (under compression) as well as shear modulus of these glasses strongly depend on the contents of their solvent $(\mathrm{Zr})$ atoms. Based on structural observations on parts of these materials, the dependence of shear modulus and yield strength on the atomic ratio of $\mathrm{Zr}$ can be understood from the weak links that locate in the solvent-rich configurations with relatively high excessive free volume.

\section{Experiments}

Ingots with the compositions of $\mathrm{Zr}_{70} \mathrm{Cu}_{13.5} \mathrm{Al}_{8} \mathrm{Ni}_{8.5} \quad\left(\mathrm{Zr}_{70}\right)$, $\mathrm{Zr}_{64.13} \mathrm{Cu}_{15.75} \mathrm{Al}_{10} \mathrm{Ni}_{10.12} \quad\left(\mathrm{Zr}_{64}\right), \quad \mathrm{Zr}_{55} \mathrm{Cu}_{30} \mathrm{Al}_{10} \mathrm{Ni}_{5} \quad\left(\mathrm{Zr}_{55}\right)$ and $\mathrm{Zr}_{50.7} \mathrm{Cu}_{28} \mathrm{Al}_{12.3} \mathrm{Ni}_{9}\left(\mathrm{Zr}_{50}\right)$ were prepared by arc-melting high purity $\mathrm{Zr}, \mathrm{Cu}, \mathrm{Al}$ and $\mathrm{Ni}$ in a argon atmosphere. Ti-getter was used to further reduce the oxygen partial pressure in the melting chamber. Cylindrical rods with a dimension of $\Phi 3 \times 30 \mathrm{~mm}$ were prepared via the coppermold suction-casting method under the same condition. The glassy state of all rods was verified by both X-ray diffraction and high resolution transmission electron microscopy (HRTEM, JEOL JEM-2100F). The

\footnotetext{
* Corresponding author.

E-mail address: jiangfeng@mail.xjtu.edu.cn (F. Jiang).
} 
Table 1

Summary of shear modulus $(G)$, yield strength $\left(\sigma_{y}\right)$, glass transition temperature $\left(T_{g}\right)$ and molar volume $\left(V_{m}\right)$ of 11 kinds of $\mathrm{Zr}$-Cu-Al-Ni metallic glasses.

\begin{tabular}{lllll}
\hline Alloys. & $G \pm 5 \%(\mathrm{GPa})$ & $\sigma_{y}(\mathrm{GPa})$ & $T_{g} \pm 5(\mathrm{~K})$ & $\begin{array}{l}V_{m}\left(\mathrm{~cm}^{3} /\right. \\
\mathrm{mol})\end{array}$ \\
\hline $\mathrm{Zr}_{72} \mathrm{Cu}_{13} \mathrm{Al}_{7.5} \mathrm{Ni}_{7.5}$ & 27 & $1.54[17]$ & $625[17]$ & 12.24 \\
$\mathrm{Zr}_{70} \mathrm{Cu}_{13.5} \mathrm{Al}_{8} \mathrm{Ni}_{8.5}$ & 27.3 & $1.57[18]$ & $625[18]$ & 12.11 \\
$\mathrm{Zr}_{65.5} \mathrm{Cu}_{22.4} \mathrm{Al}_{5.6} \mathrm{Ni}_{6.5}$ & 28.9 & $1.60[20]$ & $636[19]$ & 11.74 \\
$\mathrm{Zr}_{65} \mathrm{Cu}_{15} \mathrm{Al}_{10} \mathrm{Ni}_{10}$ & $30[15]$ & $1.65[21]$ & $652[21]$ & 11.74 \\
$\mathrm{Zr}_{64.13} \mathrm{Cu}_{15.75} \mathrm{Al}_{10} \mathrm{Ni}_{10.12}$ & $28.5[22]$ & $1.69[22]$ & $646[22]$ & 11.75 \\
$\mathrm{Zr}_{62} \mathrm{Cu}_{15.4} \mathrm{Al}_{10} \mathrm{Ni}_{12.6}$ & $29[16]$ & $1.81[16]$ & $652[16]$ & 11.67 \\
$\mathrm{Zr}_{61.88} \mathrm{Cu}_{18} \mathrm{Al}_{10} \mathrm{Ni}_{10.12}$ & $29.1[23]$ & $1.73[23]$ & $653[23]$ & 11.60 \\
$\mathrm{Zr}_{57} \mathrm{Cu}_{27} \mathrm{Al}_{11} \mathrm{Ni}_{5}$ & 32.7 & $1.84[24]$ & $682[24]$ & 11.32 \\
$\mathrm{Zr}_{55} \mathrm{Cu}_{30} \mathrm{Al}_{10} \mathrm{Ni}_{5}$ & 32.5 & $1.82[25]$ & $685[25]$ & 11.15 \\
$\mathrm{Zr}_{53} \mathrm{Cu}_{18.7} \mathrm{Al}_{16.3} \mathrm{Ni}_{12}$ & 33.4 & $1.88[26]$ & $709[28]$ & 11.16 \\
$\mathrm{Zr}_{50.7} \mathrm{Cu}_{28} \mathrm{Al}_{9} \mathrm{Ni}_{12.3}$ & 34.8 & $1.90[27]$ & $719[28]$ & 10.79 \\
\hline & & & &
\end{tabular}

thermal properties of these specimens were characterized by differential scanning calorimetry (DSC). The DSC tests were conducted in a TA Q2000 thermal-analysis instrument with a heating rate of $0.33 \mathrm{~K} / \mathrm{s}$ in a flow of argon. The base line for each DSC measurement was obtained by a second run under identical conditions. With the purpose of ensuring the reliability of the experimental data, at least three specimens for each of the metallic glass have been tested on the same instrument under identical conditions. Meanwhile, qualitative distribution of free volume in each specimen was investigated using the weak-phase object HRTEM imaging method. The specimens for both the DSC measurements and the HRTEM analyses were cut from the same position of the as-cast rods and then prepared in standard mechanical grinding to the same thickness. Furthermore, the grinded cross-sectional HRTEM specimens were milled by low-energy ion beam thinner under the same conditions.

\section{Results}

Table 1 presents the shear moduli $(G)$, yield strengths $\left(\sigma_{y}\right)$, glass transition temperatures $\left(T_{g}\right)$ and molar volumes $\left(V_{m}\right)$ of a series of $\mathrm{Zr}$ Cu-Al-Ni metallic glasses with different solvent-Zr content $\left(C_{Z r}\right.$, at.\%) [15-28]. Here, all of the yield strengths are summarized from literatures, which were carried out under uniaxial compressions at quasistatic strain rates. Under such conditions, the yield strength is an inherent material property and should be almost constant for a given metallic glass $[29,30]$. The shear moduli in both the literatures and present work were measured by ultrasonic method, which has an accuracy better than $5 \%$ [31-33]. The maximum error value of $5 \%$ is adopted in the current work. The glass transition temperatures are also summarized from literatures, which were measured by DSC. The random errors of the measured $T_{g}$ is usually less than $5 \mathrm{~K}$ [34-36]. Here, an experimental error of $5 \mathrm{~K}$ for the glass transition temperature is taken. The values of molar volumes are calculated according to the rule of mixtures [37]. As pointed out previously [15,16,38], both shear modulus $G$ and yield strength $\sigma_{y}$ showed an approximately linear dependence on the value of $T_{g} / V_{m}$. For the current studied materials, these relationships are quite similar as presented in Fig. 1a. Such correlations imply a similarity between plastic yielding and glass transition in metallic glasses $[16,22]$. Furthermore, the variations of shear modulus as well as yield strength with the solvent-Zr content are plotted in Fig. 1b. It is interesting to find that either shear modulus or yield strength has a nearly linear reduction with increasing the atomic ratio of $\mathrm{Zr}$ in these $\mathrm{Zr}$-Cu-Al-Ni metallic glasses. In addition, the shear moduli of these glasses are less than that of pure $\mathrm{Zr}$, indicating a deviation from modulus' inheritance $[8,39,40]$. Moreover, the deviation becomes larger with increasing the atomic ratio of $\mathrm{Zr}$.

The DSC curves of the $Z_{70}, Z_{64}, Z_{55}$ and $Z_{50}$ glasses are shown in Fig. 2. All curves show the distinct feature of a glass transition (marked by the arrows) before crystallization. The glass transition temperatures
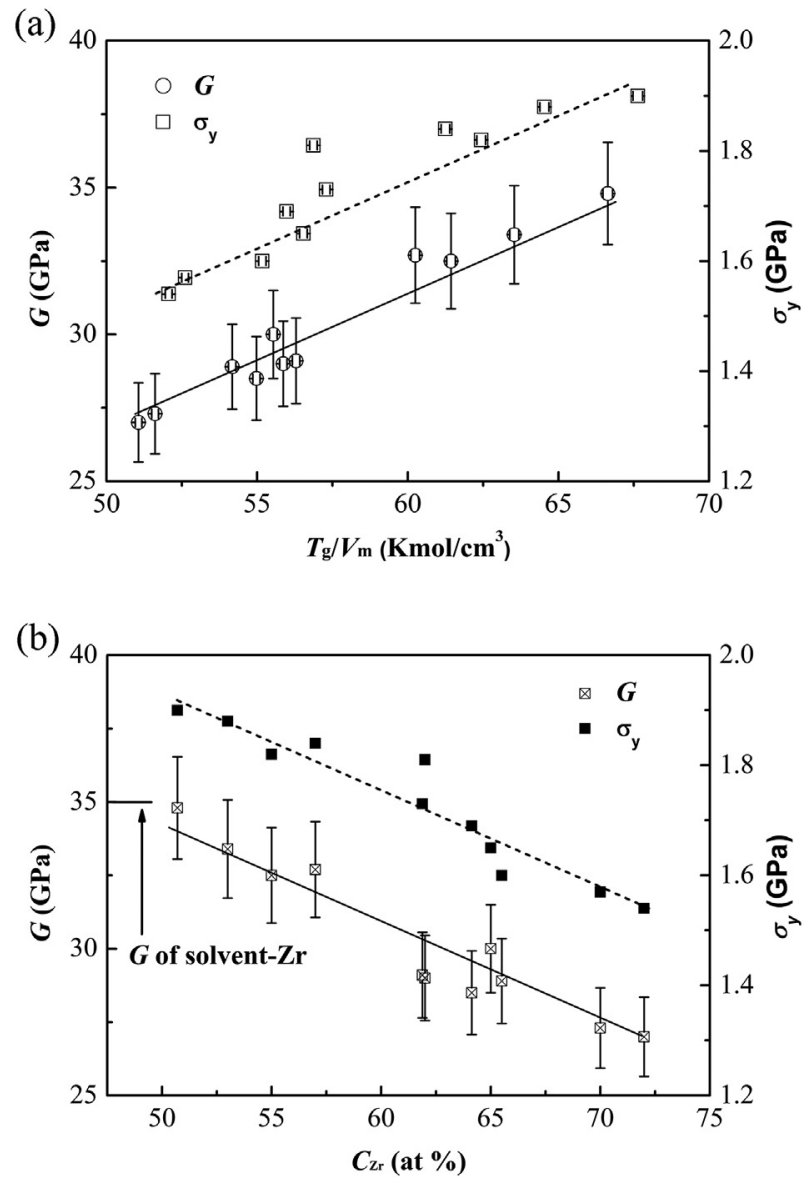

Fig. 1. The variation of shear modulus $(G)$ and yield strength $\left(\sigma_{y}\right)$ with (a) the parameter combination $\left(T_{g} / V_{m}\right)$ and (b) the atomic ratio of $\mathrm{Zr}\left(C_{Z r}\right.$, at.\%).

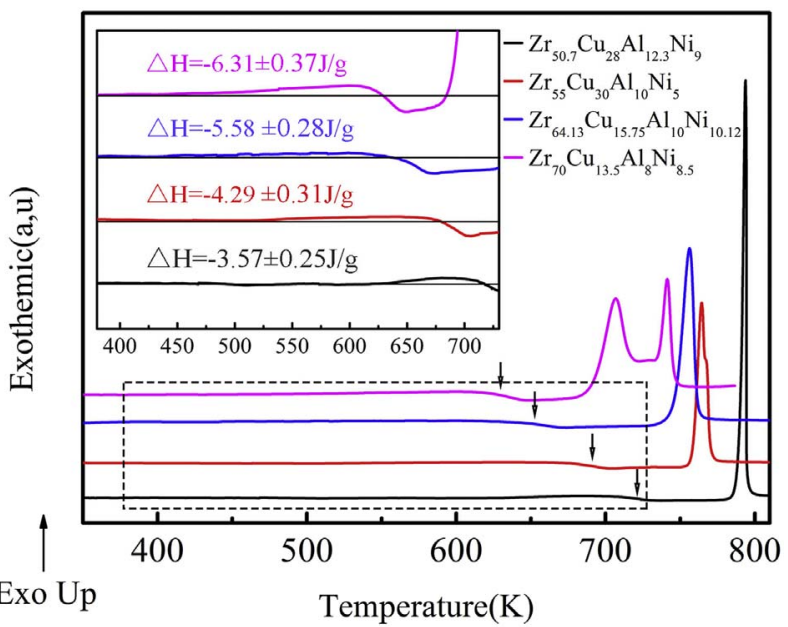

Fig. 2. DSC curves of the four $\mathrm{Zr}-\mathrm{Cu}-\mathrm{Al}-\mathrm{Ni}$ metallic glass samples. The inset shows the different exothermic signals before the glass transition among these samples.

of the four metallic glasses were measured to be about $627 \mathrm{~K}, 651 \mathrm{~K}$, $690 \mathrm{~K}$ and $719 \mathrm{~K}$, respectively. This indicates that the decrease of $\mathrm{Zr}$ content leads to an increase of $T_{g}$. Importantly, the exothermic signals before the glass transition display an apparent difference among these samples, which is presented in the inset of Fig. 2. It is well known that the exothermic enthalpy $(\Delta H)$ prior to glass transition can be directly related to the excessive free volume $\left(v_{f}\right)$ by an empirical relationship of $\Delta H=\beta^{\prime} v_{f}[41,42]$ with a constant $\beta^{\prime}$. The values of $\Delta H$, shown in the inset of Fig. 2, indicate that the free volume concentration decreases 

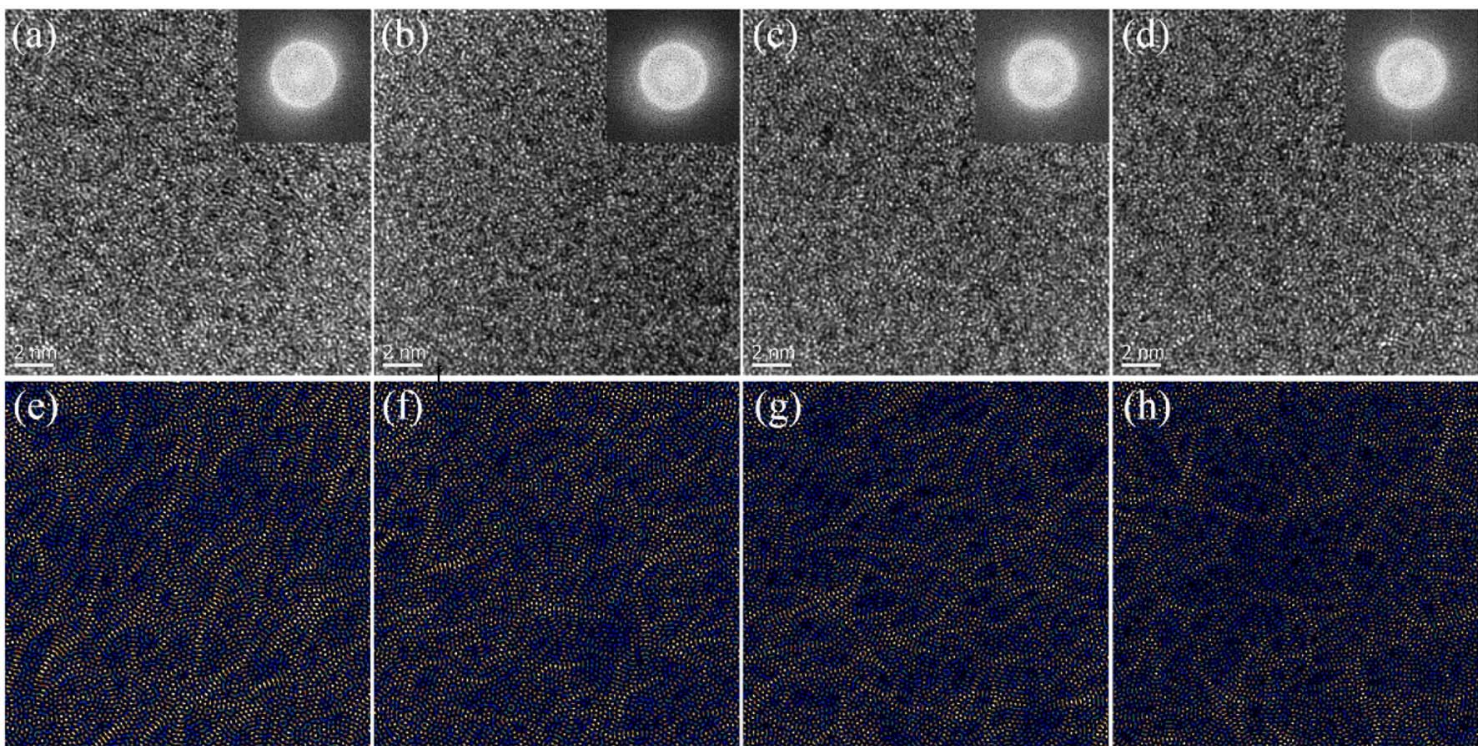

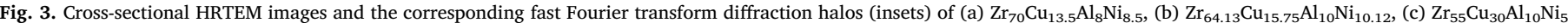

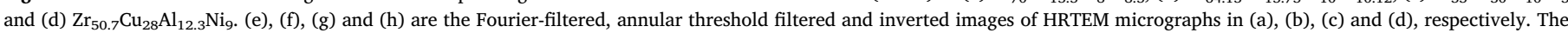

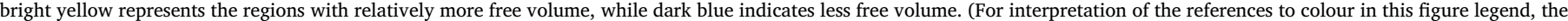
reader is referred to the web version of this article.)

monotonically with the decrease of $\mathrm{Zr}$ content.

Fig. 3a-d present the HRTEM images and the corresponding fast Fourier transform diffraction halos (insets) of the four metallic glasses. There are numbers of short-range-order clusters, which probably correspond to the locally dense-packing configurations. In order to obtain the structural information beyond short-range-order, weakphase object HRTEM imaging analysis were carried out on Fig. 3a-d. This method is developed by Miller and Gibson [43] and later extended by many other researchers $[44,45]$. The obtained Fourier-filtered, annular threshold filtered and inverted images are presented in Fig. 3e-h. During the HRTEM analysis, large flat regions were selected under nearly the same brightness of the electron beam. Therefore, the thickness of the specimens could be constant and small. In addition, the objective aperture with diameter of $60 \mu \mathrm{m}$ was used to cut off the higher-frequency oscillating information. A defocus value of approximately - $200 \mathrm{~nm}$ was set to image free volume in the metallic glasses and the images were acquired by a Gantan 830 slow-scan chargecoupled device camera. Moreover, the marked area is identical during the annular threshold filtered. Therefore, the weak phase object approximation holds in the present cases and the image's intensity comes mainly from the specimen density. More specifically, the bright regions (bright yellow) correspond to the zones with more free volume and the dark parts (dark blue) represent those with less free volume [43-45]. Such nanoscale spatial heterogeneity revealed here is consistent with those revealed by Liu et al. [46] and Yang et al. [47] with the aid of dynamic force microscopy. It is clearly revealed that the nanoscale heterogeneity highly depends on the $\mathrm{Zr}$ content. In particular, the decreasing $\mathrm{Zr}$ content gives rise to an increase of the dense packing regions and a decrease of the free volume concentration, which is in line with the DSC analysis presented in Fig. 2.

\section{Discussion}

It has been suggested that the fundamental building blocks in metallic glasses are the solute-centered atomic clusters $[48,49]$. Some of these clusters could form superclusters as they are tightly connected by sharing atoms at vertices, edges or faces [50]. The long-range disordered 3D space of metallic glasses is made up of fractal networks by connecting the solute-centered clusters and the superclusters in the form of face-centered cubic [48] or hexagonal close-packed [49].
Regions between the clusters are empty or occupied by lone atoms that do not form clusters. The former is related to the free volume, whereas the latter always corresponds to the excessive solvent atoms. In this regard, there are two types of bonds in the metallic glasses. One is the solvent-solute bonds in the clusters and the other is the solventsolvent bonds among the clusters. For the current $\mathrm{Zr}-\mathrm{Cu}-\mathrm{Al}-\mathrm{Ni}$ metallic glass, the mixing heats of $\mathrm{Zr}-\mathrm{Ni}, \mathrm{Zr}-\mathrm{Al}$ and $\mathrm{Zr}-\mathrm{Cu}$ pairs are $-49,-44$ and $-23 \mathrm{KJ} / \mathrm{mol}$, respectively, which are the most negative values among all atomic pairs [51] and even higher than that of $\mathrm{Zr}-\mathrm{Zr}$ pair. This indicates that the solvent-solvent bonds are softer than the solventsolute ones. In addition, the preferential concentrating of free volume around the biggest $\mathrm{Zr}$ atoms [28,52] will further softening the solventsolvent junctions between the clusters. Moreover, it is found that the bond exchange propensity of $\mathrm{Zr}$ atoms was larger than other constituents [53]. This implies that the shear resistance of the solvent-solvent junctions will be lower than that of the solvent-solute bonds. Consequently, the solvent-solvent bonds and the free volume concentrated around them will constitute the weakest configurations in the present glassy structure. In such a scenario, metallic glasses can be treated as atomic level dual phase with different stiffness as schematized in Fig. 4, where $\mathrm{A}, \mathrm{B}$ and $\mathrm{C}$ denotes the excessive solvent atoms, the solutecentered clusters and the superclusters, respectively. The stiff phase represents the solute-centered clusters and the superclusters where the atoms are tightly bonded, while the less stiff one corresponds to the solvent-solvent bonds and free volume, namely the weakest configurations in the glassy structure. Therefore, the global elastic modulus of the metallic glass is the weighted average of elastic moduli of the two constitute phase, according to the "rule of mixtures" [7,54,55].

In the present $\mathrm{Zr}$-Cu-Al-Ni metallic glass with a higher $\mathrm{Zr}$ content (Fig. 4a), there are many excessive solvent atoms (Zr), which randomly distribute and loosely occupy the junctions among the densely packed clusters. Furthermore, the larger amount of excessive solvent atoms will induce more free volume concentrated in the junctions. Hence, there are more weakest configurations in the glass structure. Correspondingly, the amount of the weakest configurations will be less in the metallic glass with a lower $\mathrm{Zr}$ content, as shown in Fig. 4b. Above scenario agrees well with the experimental results of indirect DSC measurement (Fig. 2) and qualitative HRTEM analysis (Fig. 3). Accordingly, it can be concluded that there are more weakest configurations in the metallic glass with a higher $\mathrm{Zr}$ content. In other words, the fraction 
(a)

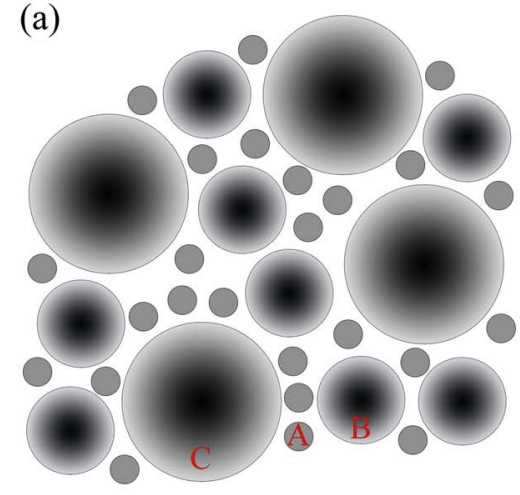

(b)

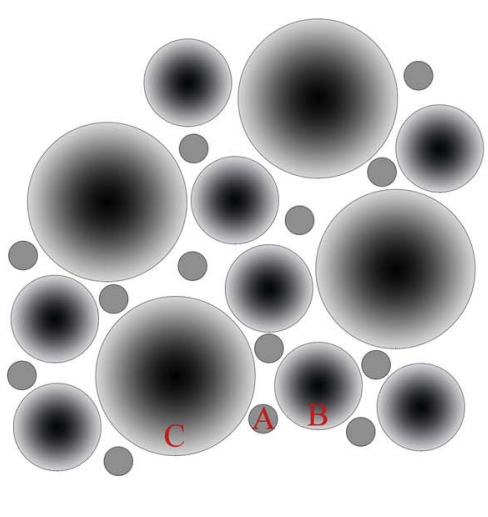

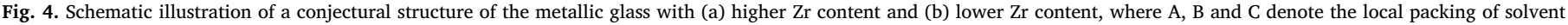
atoms (Zr), solute-centered clusters and superclusters, respectively.

of the less stiff phase will be larger, whereas that of the stiff phase will be smaller. Therefore, the global elastic modulus of the metallic glass becomes lower with increasing $\mathrm{Zr}$ content, which is verified by the observed linear reduction of shear modulus with increasing atomic ratio of $\mathrm{Zr}$ presented in Fig. 1b. It must be addressed that the shear moduli of all the metallic glasses are lower than that of the solvent atoms. Specifically, there is a larger deviation of the modulus' inheritances $[8,39,40]$ in the metallic glass with higher atom ratio of Zr. It indicates that the shear resistance decreases when the $\mathrm{Zr}$ content increases, which is due to the following two reasons: (i) more solvent atoms concentrated in the junctions in turn decrease the shear resistance of the junctions due to the preferential bond exchange of $\mathrm{Zr}$ atoms; (ii) higher concentration of free volume further softens the solvent-solvent bonds.

For metallic glasses, the shear transformations (STs), i.e. the inelastic rearrangements of local atomic groups, is usually regarded as the fundamental unit of plastic deformation [56-58]. It is proposed that the total potential energy barrier for an ST in a glass is [14]: $W=$ $\left(8 / \pi^{2}\right) G \gamma_{C}{ }^{2} \zeta \Omega$, where $\Omega$ is the characteristic volume of the ST that falls in a narrow range for various metallic glasses. $\zeta$ is a correction factor and $\gamma_{C}$ is the critical shear strain that is nearly a constant in metallic glasses. Consequently, the ST events can be preferentially activated at the weakest configurations due to their low shear modulus. In a metallic glass specimen experiencing a uniaxial stress lower than the yield strength, the solute-centered clusters and the superclusters act as the elastic backbone, while the scattered ST events activated at the weakest configurations contribute to the inelastic part [59]. As long as the isolated ST events do not percolate to a sizable length-scale, they can be reversed with the aid of the back-stress from the backbone upon unloading and the metallic glass behaves elastically on the macroscopic scale $[60,61]$. As the external stress keeps increasing, there will be more and more activated ST events, and meanwhile the associated atomic rearrangements in the ST events can relax the local stress and reduce the local energy concentration. In order to counterbalance this drop in local stress, atoms in the surrounding region will be absorbed into the ST events. When the external stress increases to a critical value, the activated ST events will expand outwards and combine with each other. It leads to the formation of one mature shear band. Then the elastic backbone will be penetrated and give rise to irreversible macroscopic yield of the metallic glass $[62,63]$. For the current model metallic glass with a higher atomic ratio of $\mathrm{Zr}$, there will be more potential ST sites due to the larger amount of weakest configurations. The more weakest configurations coupled with the higher free volume concentration correspond to a larger amount of activated ST events and an easier growth of them. Consequently, the critical stress for the formation of a mature shear band will be less. This corresponds to the lower yield strength of the metallic glass with a higher $\mathrm{Zr}$ content, as indicated by the observation on the monotonous decrease of $\sigma_{y}$ with increasing $C_{Z r}$ in
Fig. 1b.

It is worthy to note that the direct dependence of the yield strength on the $\mathrm{Zr}$ content in the $\mathrm{Zr}$-Cu-Al-Ni metallic glasses is likely to be extended to other Zr-based metallic glass systems which have the same chemical constituents. As presented in Table S1 (Supplementary material), many other Zr-based metallic glass systems also obey the correlation that increasing the atomic ratio of solvent atom leads to a decrease of shear modulus. As mentioned above, this also means a decrease of yield strength with increasing $\mathrm{Zr}$ content. Additionally, as listed in Table S2 (Supplementary material), parts of other metallic glass systems with the identical chemical constituents and the same solvent atom also follow the unique correlation observed above. Nevertheless, we still believe that some metallic glasses systems will not follow this correlation if they are not metallic bond dominated. This is because metallic and metalloid bonds should play very different roles on the strength of metallic glasses. The associated cases are deserved to be studied in detailed. Furthermore, it is interesting to note that the current correlation between the yield strength and the atomic ratio of $\mathrm{Zr}$ is analogous to the dependence of the yield strength on the amount of the flow units reported by other researchers [64-66]. In fact, both of them can be attributed to the preferential straining of the localized weakest configurations. This further rationalizes the uncovered relationship between yield strength and the content of $\mathrm{Zr}$ atoms in the $\mathrm{Zr}$ Cu-Al-Ni metallic glasses.

Moreover, our findings may provide a guideline for further strengthening the present $\mathrm{Zr}-\mathrm{Cu}-\mathrm{Ni}$-Al metallic glasses, where decreasing solvent $\mathrm{Zr}$ or increasing solute $\mathrm{Cu}, \mathrm{Ni}$ and $\mathrm{Al}$ can lead to higher yield strength. Besides, this will not change their solvent-solute status and harm the glass forming ability. Since the $\mathrm{Zr}-\mathrm{Ni}$ bond has the most negative mixing enthalpy among all bonds [51], Ni is probably more effective to strengthen the present $\mathrm{Zr}-\mathrm{Cu}-\mathrm{Ni}$-Al metallic glass system, as compared to $\mathrm{Cu}$ and $\mathrm{Al}$.

\section{Conclusion}

It is found that both shear modulus and yield strength in the $\mathrm{Zr}-\mathrm{Cu}$ Al-Ni metallic glass system show a nearly linear decrease with increasing the atomic ratio of $\mathrm{Zr}$. This finding can be well explained by the activation and the accumulation of STs that occur in the weakest configurations. Our finding implies that the weakest configurations in glasses determine not only shear modulus $[8,12]$ but also yield strength. Moreover, it may contribute to design metallic glasses with higher strength by simply altering atomic ratio of the constituents.

\section{Acknowledgements}

The financial support from the National Natural Science Foundation of China (NSFC) under Grant nos. 51171138, 11522221, 11372315 and 
51321003 are gratefully acknowledged. This work was also supported by a grant from Major Fundamental Research Projects of National Security (No. 613262).

\section{Appendix A. Supplementary data}

Supplementary data to this article can be found online at http://dx. doi.org/10.1016/j.jnoncrysol.2017.04.021.

\section{References}

[1] X. Yue, A. Inoue, C.-T. Liu, C. Fan, The development of structure model in metallic glasses, Mater. Res. 0318 (2017) 1-13.

[2] D.Z. Chen, C.Y. Shi, Q. An, Q. Zeng, W.L. Mao, W.A. Goddard, J.R. Greer, Fractal atomic-level percolation in metallic glasses, Science 349 (2015) 1306-1310.

[3] S.D. Feng, L. Qi, L.M. Wang, P.F. Yu, S.L. Zhang, M.Z. Ma, X.Y. Zhang, Q. Jing, K.L. Ngai, A.L. Greer, G. Li, R.P. Liu, Structural feature of $\mathrm{Cu}_{64} \mathrm{Zr}_{36}$ metallic glass on nanoscale: densely-packed clusters with loosely-packed surroundings, Scr. Mater. 115 (2016) 57-61.

[4] Y.L. Sun, Y.J. Sun, H.M. Li, Cluster deviation degree in Lennard-Jones glass-forming liquid, J. Non-Cryst. Solids 455 (2017) 59-61.

[5] P. Zhang, J.J. Maldonis, M.F. Besser, M.J. Kramer, P.M. Voyles, Medium-range structure and glass forming ability in $\mathrm{Zr}-\mathrm{Cu}-\mathrm{Al}$ bulk metallic glasses, Acta Mater. 109 (2016) 103-114.

[6] H. Liu, Q. Liu, H. Su, W. Yang, Y. Zhao, J. Huo, B. Shen, Atomic-scale structural heterogeneity and elastic modulus for metallic glasses, J. Non-Cryst. Solids 426 (2015) 137-140.

[7] W. Zhao, J.L. Cheng, S.D. Feng, G. Li, R.P. Liu, Intrinsic correlation between elastic modulus and atomic bond stiffness in metallic glasses, Mater. Lett. 175 (2016) $227-230$.

[8] D. Ma, A.D. Stoica, X.L. Wang, Z.P. Lu, B. Clausen, D.W. Brown, Elastic modul inheritance and the weakest link in bulk metallic glasses, Phys. Rev. Lett. 108 (2012) 085501-085504.

[9] X. Huang, Z. Ling, Y.J. Wang, L.H. Dai, Intrinsic structural defects on medium range in metallic glasses, Intermetallics 75 (2016) 36-41.

[10] S. Gelin, H. Tanaka, A. Lemaitre, Anomalous phonon scattering and elastic correlations in amorphous solids, Nat. Mater. 15 (2016) 1177-1181.

[11] R. Busselez, T. Pezeril, V.E. Gusev, Structural heterogeneities at the origin of acoustic and transport anomalies in glycerol glass-former, J. Chem. Phys. 140 (2014) 234505-234514.

[12] J. Ding, Y.Q. Cheng, H. Sheng, M. Asta, R.O. Ritchie, E. Ma, Universal structural parameter to quantitatively predict metallic glass properties, Nat. Commun. 7 (2016) 13733-13742.

[13] J.C. Dyre, N.B. Olsen, T. Christensen, Local elastic expansion model for viscous-flow activation energies of glass-forming molecular liquids, Phys. Rev. B 53 (1996) $2171-2174$.

[14] W.L. Johnson, K. Samwer, A universal criterion for plastic yielding of metallic glasses with a $\left(\mathrm{T} / \mathrm{T}_{\mathrm{g}}\right)^{(2 / 3)}$ temperature dependence, Phys. Rev. Lett. 95 (2005) 195501-195504.

[15] R.T. Qu, Z.Q. Liu, R.F. Wang, Z.F. Zhang, Yield strength and yield strain of metallic glasses and their correlations with glass transition temperature, J. Alloys Compd. 637 (2015) 44-54.

[16] Y.H. Liu, C.T. Liu, W.H. Wang, A. Inoue, T. Sakurai, M.W. Chen, Thermodynamic origins of shear band formation and the universal scaling law of metallic glass strength, Phys. Rev. Lett. 103 (2009) 65504-65507.

[17] X. Hui, S.N. Liu, S.J. Pang, L.C. Zhuo, T. Zhang, G.L. Chen, Z.K. Liu, High-zirconiumbased bulk metallic glasses with large plasticity, Scr. Mater. 63 (2010) 239-242.

[18] Y.H. Li, W. Zhang, C. Dong, J.B. Qiang, K. Yubuta, A. Makino, A. Inoue, Unusual compressive plasticity of a centimeter-diameter Zr-based bulk metallic glass with high Zr content, J. Alloys Compd. 504 (2010) 2-5.

[19] W. Chen, Y. Wang, J. Qiang, C. Dong, Bulk metallic glasses in the Zr-Al-Ni-Cu system, Acta Mater. 51 (2003) 1899-1907.

[20] N.H. Tariq, H.B. Awais, J.I. Akhter, M. Naeem, A. Ahmad, Plasticity enhancement in centrally confined Zr-based bulk metallic glass, Int. J. Mater. Res. 103 (2012) 620-623.

[21] W.H. Li, B.C. Wei, T.H. Zhang, L.C. Zhang, Y.D. Dong, Mechanical behavior of $\mathrm{Zr}_{65} \mathrm{Al}_{10} \mathrm{Ni}_{10} \mathrm{Cu}_{15}$ and $\mathrm{Zr}_{52.5} \mathrm{Al}_{10} \mathrm{Ni}_{10} \mathrm{Cu}_{15} \mathrm{Be}_{12.5}$ bulk metallic glasses, Mater. Trans. 46 (2005) 2954-2958.

[22] W.H. Wang, Correlation between relaxations and plastic deformation, and elastic model of flow in metallic glasses and glass-forming liquids, J. Appl. Phys. 110 (2011) 053521-053536.

[23] Y.H. Liu, G. Wang, R.J. Wang, M.X. Pan, W.H. Wang, Super plastic bulk metallic glasses at room temperature, Science 315 (2007) 1385-1388.

[24] S. Jana, R. Bhowmick, Y. Kawamura, K. Chattopadhyay, U. Ramamurty, Deformation morphology underneath the Vickers indent in a Zr-based bulk metallic glass, Intermetallics 12 (2004) 1097-1102.

[25] T. Hirano, H. Kato, A. Matsuo, Y. Kawamura, A. Inoue, Synthesis and mechanical properties of $\mathrm{Zr}_{55} \mathrm{Al}_{10} \mathrm{Ni}_{5} \mathrm{Cu}_{30}$ bulk glass composites containing $\mathrm{ZrC}$ particles formed by the in-situ reaction, Mater. Trans. 41 (2000) 1454-1459.

[26] D.D. Qu, K.D. Liss, Y.J. Sun, M. Reid, J.D. Almer, K. Yan, Y.B. Wang, X.Z. Liao, J. Shen, Structural origins for the high plasticity of a $\mathrm{Zr}-\mathrm{Cu}-\mathrm{Ni}-\mathrm{Al}$ bulk metallic glass, Acta Mater. (2012) 321-330.
[27] W. Zheng, Y.J. Huang, G.Y. Wang, P.K. Liaw, J. Shen, Influence of strain rate on compressive deformation Behavior of a $\mathrm{Zr}-\mathrm{Cu}-\mathrm{Ni}$-Al bulk metallic glass at room temperature, Metall. Mater. Trans. A 42 (2011) 1491-1498.

[28] Y.J. Sun, D.D. Qu, Y.J. Huang, K.D. Liss, X.S. Wei, D.W. Xing, J. Shen, Zr-Cu-Ni-Al bulk metallic glasses with superhigh glass-forming ability, Acta Mater. 57 (2009) 1290-1299.

[29] L. Liu, Z. Cai, H. Li, S. Guo, G. Zhang, The correlation between the pressure sensitivity and the fragility/glass transition temperature in bulk metallic glasses, J. Non-Cryst. Solids 357 (2011) 3033-3035.

[30] M. Zhou, K. Hagos, H. Huang, M. Yang, L. Ma, Improved mechanical properties and pitting corrosion resistance of $\mathrm{Zr}_{65} \mathrm{Cu}_{17.5} \mathrm{Fe}_{10} \mathrm{Al}_{7.5}$ bulk metallic glass by isothermal annealing, J. Non-Cryst. Solids 452 (2016) 50-56.

[31] Y. Cheng, C. Chen, M. Shi, T. Zhang, Synthesis of CoCrMoCB bulk metallic glasses with high strength and good plasticity via regulating the metalloid content, J. NonCryst. Solids 410 (2015) 155-159.

[32] W.H. Wang, Correlations between elastic moduli and properties in bulk metallic glasses, J. Appl. Phys. 99 (2006) 093506-0935016.

[33] Y.P. Mitrofanov, K. Csach, A. Juríková, J. Miškuf, W.H. Wang, V.A. Khonik, Densification-induced heat release upon structural relaxation of Zr-based bulk metallic glasses, J. Non-Cryst. Solids 448 (2016) 31-35.

[34] R. Limbach, K. Kosiba, S. Pauly, U. Kühn, L. Wondraczek, Serrated flow of CuZr based bulk metallic glasses probed by nanoindentation: role of the activation barrier, size and distribution of shear transformation zones, J. Non-Cryst. Solids 459 (2017) 130-141.

[35] C.C. Dun, H.S. Liu, B.L. Shen, Enhancement of plasticity in Co-Nb-B ternary bulk metallic glasses with ultrahigh strength, J. Non-Cryst. Solids 358 (2012) 3060-3064.

[36] Q. Liu, H. Liu, M. Wang, Y. Zhang, Z. Ma, Y. Zhao, W. Yang, Effects of Ni substitution for $\mathrm{Fe}$ on magnetic properties of $\mathrm{Fe}_{80}-\mathrm{xNixP}_{13} \mathrm{C}_{7(\mathrm{x}}=0-$ 30) glassy ribbons, J. Non-Cryst. Solids 463 (2017) 68-71.

[37] D. Ma, A.D. Stoica, X.L. Wang, Volume conservation in bulk metallic glasses, Appl. Phys. Lett. 91 (2007) 021905-021908.

[38] B. Yang, C.T. Liu, T.G. Nieh, Unified equation for the strength of bulk metallic glasses, Appl. Phys. Lett. 88 (2006) 221911-221914.

[39] W.H. Wang, Metallic glasses: family traits, Nat. Mater. 11 (2012) 275-276.

[40] W.H. Wang, Properties inheritance in metallic glasses, J. Appl. Phys. 111 (2012) (123519-123517).

[41] A. Slipenyuk, J. Eckert, Correlation between enthalpy change and free volume reduction during structural relaxation of $\mathrm{Zr}_{55} \mathrm{Cu}_{30} \mathrm{Al}_{10} \mathrm{Ni}_{5}$ metallic glass, Scr. Mater. 50 (2004) 39-44.

[42] F. Jiang, M.Q. Jiang, H.F. Wang, Y.L. Zhao, L. He, J. Sun, Shear transformation zone volume determining ductile-brittle transition of bulk metallic glasses, Acta Mater. 59 (2011) 2057-2068.

[43] P.D. Miller, M.J. Gibson, Connecting small-angle diffraction with real-space images by quantitative transmission electron microscopy of amorphous thin-films, Ultramicroscopy 74 (1998) 221-235.

[44] Z.W. Zhu, L. Gu, G.Q. Xie, W. Zhang, A. Inoue, H.F. Zhang, Z.Q. Hu, Relation between icosahedral short-range ordering and plastic deformation in Zr-Nb-Cu-Ni-Al bulk metallic glasses, Acta Mater. 59 (2011) 2814-2822.

[45] Z.Q. Chen, L. Huang, F. Wang, P. Huang, T.J. Lu, K.W. Xu, Suppression of annealing-induced embrittlement in bulk metallic glass by surface crystalline coating, Mater. Des. 109 (2016) 179-185.

[46] Y.H. Liu, D. Wang, K. Nakajima, W. Zhang, A. Hirata, T. Nishi, A. Inoue, M.W. Chen, Characterization of nanoscale mechanical heterogeneity in a metallic glass by dynamic force microscopy, Phys. Rev. Lett. 106 (2011) 125504-125507.

[47] Y. Yang, J.F, Zeng, A. Volland, J.J. Blandin, S. Gravier, C.T. Liu, Fractal growth of the dense-packing phase in annealed metallic glass imaged by high-resolution atomic force microscopy, Acta Mater. 60 (2012) 5260-5272.

[48] D.B. Miracle, A structural model for metallic glasses, Nat. Mater. 3 (2004) 697-702.

[49] H.W. Sheng, W.K. Luo, F.M. Alamgir, J.M. Bai, E. Ma, Atomic packing and short-tomedium-range order in metallic glasses, Nature 439 (2006) 419-425.

[50] D. Ma, A.D. Stoica, X.L. Wang, Power-law scaling and fractal nature of mediumrange order in metallic glasses, Nat. Mater. 8 (2009) 30-34.

[51] A. Takeuchi, A. Inoue, Classification of bulk metallic glasses by atomic size difference, heat of mixing and period of constituent elements and its application to characterization of the main alloying element, Mater. Trans. 46 (2005) 2817-2829.

[52] M. Wakeda, Y. Shibutani, S. Ogata, J. Park, Relationship between local geometrica factors and mechanical properties for $\mathrm{Cu}-\mathrm{Zr}$ amorphous alloys, Intermetallics 15 (2007) 139-144.

[53] W. Jiao, X.L. Wang, S. Lan, S.P. Pan, Z.P. Lu, Propensity of bond exchange as a window into the mechanical properties of metallic glasses, Appl. Phys. Lett. 106 (2015) 061910-061915.

[54] L.S. Huo, J.F. Zeng, W.H. Wang, C.T. Liu, Y. Yang, The dependence of shear modulus on dynamic relaxation and evolution of local structural heterogeneity in a metallic glass, Acta Mater. 61 (2013) 4329-4338.

[55] Z.Q. Liu, Z.F. Zhang, Universal softening and intrinsic local fluctuations in metallic glasses, Appl. Phys. Lett. 103 (2013) 181901-181905.

[56] C. Wang, Q.P. Cao, X.D. Wang, D.X. Zhang, U. Ramamurty, R.L. Narayan, J.Z. Jiang, Intermediate temperature brittleness in metallic glasses, Adv. Mater. 29 (2017) 1605537-1605542.

[57] M.C. Li, M.Q. Jiang, S. Yang, F. Jiang, L. He, J. Sun, Effect of strain rate on yielding strength of a Zr-based bulk metallic glass, Mater. Sci. Eng. A 680 (2017) 21-26.

[58] M.Q. Jiang, G. Wilde, L.H. Dai, Shear band dilatation in amorphous alloys, Scr. Mater. 127 (2017) 54-57.

[59] Y.F. Ye, X.D. Liu, S. Wang, J. Fan, C.T. Liu, Y. Yang, The kinetic origin of delayed yielding in metallic glasses, Appl. Phys. Lett. 108 (2016) 251901-251905. 
[60] Y.Q. Cheng, E. Ma, Atomic-level structure and structure-property relationship in metallic glasses, Prog. Mater. Sci. 56 (2011) 379-473.

[61] J.S. Harmon, M.D. Demetriou, W.L. Johnson, K. Samwer, Anelastic to plastic transition in metallic glass-forming liquids, Phys. Rev. Lett. 99 (2007) $135502-135505$

[62] Z.Y. Liu, Y. Yang, C.T. Liu, Yielding and shear banding of metallic glasses, Acta Mater. 61 (2013) 5928-5936.

[63] S. Wang, Y.F. Ye, B.A. Sun, C.T. Liu, S.Q. Shi, Y. Yang, Softening-induced plastic flow instability and indentation size effect in metallic glass, J. Mech. Phys. Solids 77
(2015) 70-85.

[64] S.V. Ketov, Y.H. Sun, S. Nachum, Z. Lu, A. Checchi, A.R. Beraldin, H.Y. Bai, W.H. Wang, D.V. Louzguine-Luzgin, M.A. Carpenter, A.L. Greer, Rejuvenation of metallic glasses by non-affine thermal strain, Nature 524 (2015) 200-203.

[65] T.P. Ge, W.H. Wang, H.Y. Bai, Revealing flow behaviors of metallic glass based on activation of flow units, J. Appl. Phys. 119 (2016) 204905-204909.

[66] A. Gulzar, Z.G. Zhu, K. Shahzad, D.Q. Zhao, W.H. Wang, Flow units perspective on sensitivity and reliability of metallic glass properties, Intermetallics 69 (2016) 98-102. 